Received: 29 January 2019

Accepted: 15 May 2019

Published online: 27 May 2019

\section{Combinatorial evaluation of phase formation and magnetic properties of FeMnCoCrAl high entropy alloy thin film library}

\begin{abstract}
A. Marshal ${ }^{1}$, K. G. Pradeep ${ }^{1}$, D. Music ${ }^{1}$, L. Wang ${ }^{2}$, O. Petracic ${ }^{2}$ \& J. M. Schneider ${ }^{1}$
We report on the influence of the Al content (from 3.5 to 54 at.\%) on phase formation and magnetic properties in FeMnCoCrAl high entropy alloy thin film libraries. Al additions to $\mathrm{FeMnCoCr}$ crystallizing in the alpha-Mn structure cause the formation of the body centered cubic (BCC) structure. This is consistent with density functional theory predictions as $\mathrm{Al}$ additions give rise to a larger stability for the BCC phase compared to the face centered cubic phase (FCC) which can be rationalized by the formation of a pseudogap at the Fermi level indicating the stabilization of the BCC phase over the FCC phase. Al additions to paramagnetic FeMnCoCr induce ferromagnetism. The largest saturation magnetization was measured for the film containing 8 at.\% of Al. As the concentration of non-ferromagnetic $\mathrm{Al}$ is increased beyond 8 at.\%, the number density of the ferromagnetic species is decreased causing a concomitant decrease in magnetization. This trend is consistent with ab initio predictions of the Al concentration induced changes in the magnetic moment. Based on the experimental and theoretical results presented here the effect of the Al concentration on the phase formation and the magnetic properties of FeMnCoCrAl thin film library can be rationalized.
\end{abstract}

Multi principal element high entropy alloys (HEA) ${ }^{1,2}$ have attracted a lot of attention because of their unusual properties $^{3,4}$. Reports suggest that the mechanical performance of some of these alloys ${ }^{3,4}$ surpasses the performance of conventional alloys, for instance, combined increase in strength and ductility ${ }^{3}$ and improved mechanical properties at cryogenic temperatures ${ }^{4}$. These alloys are composed of multiple elements with equiatomic or near equiatomic concentrations exhibiting different crystal structures and magnetic properties ${ }^{1}$. In this work we adhere to the HEA definition of Yeh et al.: HEAs are "composed of five or more principal elements" and "HEAs may contain principal elements with the concentration of each element being between 35 and 5 at. $\%{ }^{1 "}$. According to Yeh et al. ${ }^{1}$ a large negative mixing entropy in a multicomponent metallic system lowers the tendency for ordering and/or segregation, thereby promoting the formation of random solid solutions. Nonetheless, several studies revealed that the configurational entropy is not the only criterion determining phase formation and that the equiatomic alloys are not necessarily characterized by superior properties ${ }^{5,6}$. Also the formation of phases in addition to a single solid solution phase has been observed ${ }^{6,7}$. Recently, non-equiatomic HEAs, where the concentration of one or more of its constituents are varied to tailor the properties, have attained significant interest ${ }^{3,5,8,9}$. In fact, they even outperform some of their equiatomic variants, regarding mechanical properties ${ }^{3,9}$. The equiatomic FeMnCrCo HEA exhibits a multiphase microstructure with brittle Cr rich sigma phase as one of its phase constituent ${ }^{9}$. Whereas, the non-equiatomic $\mathrm{Fe}_{40} \mathrm{Mn}_{40} \mathrm{Cr}_{10} \mathrm{Co}_{10} \mathrm{HEA}$ forms a single FCC phase with high tensile strength and elongation owing to twinning induced plasticity at room temperatures ${ }^{9}$. Likewise, the superior strength-ductility combination of the non-equiatomic $\mathrm{Fe}_{50} \mathrm{Mn}_{30} \mathrm{Cr}_{10} \mathrm{Co}_{10}$ is attributed to the transformation induced plasticity and microstructural design ${ }^{10}$

With HEAs at the brink of application ${ }^{4}$, most of the reported work on HEAs were focused towards microstructure and mechanical behavior ${ }^{3,4}$. Limited studies on functional (including magnetic) properties of HEAs have been reported ${ }^{11-15}$. For example Lucas et al. described a tunable magnetic transition temperature as a function of Pd content in the FeNiCoCrPd HEA system ${ }^{12}$, making them suitable for magnetic refrigeration applications.

${ }^{1}$ Materials Chemistry, RWTH Aachen University, Kopernikusstr. 10, 52074, Aachen, Germany. ${ }^{2}$ Jülich Centre for Neutron Science JCNS and Peter Grünberg Institute PGI, JARA-FIT, Forschungszentrum Jülich GmbH, 52425, Jülich, Germany. Correspondence and requests for materials should be addressed to A.M. (email: marshalamal@gmail.com) 
FCC FeCoNi $(\mathrm{AlSi} \mid)_{\mathrm{x}}$ based HEAs were reported to exhibit saturation magnetization $\left(\mathrm{M}_{\mathrm{s}}\right)$ values as large as $1.15 \mathrm{~T}$ at room temperature ${ }^{14}$. However, FeNiCoCr and FeMnCoCrNi FCC HEA systems exhibit room temperature paramagnetism ${ }^{12}$, while $\mathrm{Al}_{\mathrm{x}} \mathrm{CoCrFeNi}^{11}$ as well as $\mathrm{Al}_{\mathrm{x}} \mathrm{CrCuFeNi}_{2}{ }^{16}$ are ferromagnetic at room temperature. It was reported that the presence of a secondary ordered Al-Ni phase in $\mathrm{AlCoCrFeNi}$ decreases the overall $\mathrm{M}_{\mathrm{s}}{ }^{11}$ and that $\mathrm{Al}$ additions to $\mathrm{CoCrFeNi}{ }^{11}$ and $\mathrm{CrCuFeNi}_{2}{ }^{16}$ cause the phase transition from paramagnetic FCC to ferromagnetic BCC structures ${ }^{11,16}$.

Soft magnetic metallic alloys play a prominent role in energy applications ${ }^{17}$. However, conventional soft magnets have their own shortcomings, such as the complicated processing of Fe-Si steels ${ }^{18}$ and the sophisticated procedure involved in the synthesis of nano-crystalline alloys ${ }^{17}$. Nano-crystalline Fe based alloys are used in magnetic applications, such as power transformers, because they exhibit superior soft magnetic properties such as negligible coercivity $\left(\mathrm{H}_{\mathrm{c}}\right)^{19}$. However, these alloys are known to behave in a brittle manner after heat treatment ${ }^{19}$.

Recently, we reported the formation of BCC solid solutions in FeMnCoCrAl HEA thin films ${ }^{20}$ by combinatorial synthesis ${ }^{21}$, where phase formation and elastic properties were in good agreement with ab initio predictions and bulk processed alloys ${ }^{20}$. This alloy contains ferromagnetic Fe and Co, as well as Mn which is known to increase the total magnetic moment as observed in Heusler alloys ${ }^{22}$. A wide single BCC stabilizing concentration range of 14 to 26 at.\% $\mathrm{Al}$ had been identified ${ }^{20}$. In this study, the major emphasis is placed on the Al concentration dependence of BCC phase formation and the resulting magnetic properties. To this end, the $\mathrm{Al}$ concentration is varied from 0 to 54 at.\% in an effort to determine the $\mathrm{Al}$ solubility range in the BCC phase, and to determine the magnetic properties thereof. Hence, the influence of the $\mathrm{Al}$ concentration ranging from 3.5 to 13 and 27 to 54 at.\% on the phase formation is explored here for the first time. In terms of magnetic properties, the $\mathrm{Al}$ concentration range of 0 to 40 at.\% is investigated also for the first time. The here adopted research strategy based on combinatorial thin film growth combined with standard as well as nm-scale spatial resolution characterization techniques is shown to be efficient in identifying the complex interplay between composition variation, phase formation and magnetic properties and may serve as a prototype for the efficient identification of composition ranges worthwhile for future in depth investigations.

\section{Results and Discussions}

Phase formation as a function a chemical composition. Five compositionally graded FeMnCoCrAl thin films were deposited, as depicted in Fig. 1(a,b), to study the influence of the Al concentration on phase formation and magnetic properties. The FeMnCoCrAl thin film spreads were characterized by energy dispersive $\mathrm{X}$-ray (EDX) analysis and X-ray diffraction (XRD) regarding chemical composition and phase formation, respectively. The $\mathrm{Al}$ concentration was varied from $3.5 \pm 0.7$ to $54.0 \pm 0.7$ at. $\%$ substituting FeMn. For all as-grown thin film composition spreads the $\mathrm{Fe} / \mathrm{Mn}$ ratio was $1.0 \pm 0.14$ and the $\mathrm{Co} / \mathrm{Cr}$ was $1.0 \pm 0.1$ along the $\mathrm{Al}$ concentration gradient (FeMn $\rightarrow \mathrm{Al}$, see Fig. 1 (b)). The $\mathrm{Co}$ and $\mathrm{Cr}$ contents were constant at $\sim 24,21,20,16$ and 13 at.\% in their respective thin films (1, 2, 3, 4 and 5) along the $\mathrm{Al}$ gradient direction as depicted in Fig. 1(b). Composition gradients also exist in the Co to $\mathrm{Cr}$ direction, but its impact on phase formation and properties is beyond the scope of this work.

The equiatomic FeMnCoCr ( 0 at.\% $\mathrm{Al})$ composition was compared to the $\mathrm{Al}$ containing combinatorial thin films. Structural analysis by XRD shows the phase evolution and lattice parameter variation as a function of $\mathrm{Al}$ concentration (Fig. 1(c)). In the upcoming discussions, the FeMnCoCrAl thin films are denoted by the $\mathrm{Al}$ concentration in at.\% (please refer Fig. 1(b)). The thin film with 0 at. $\%$ of $\mathrm{Al}$ crystallizes in the $\alpha$-Mn structure. An additional BCC phase forms upon addition of 4 at.\% of $\mathrm{Al}$ (the characterization region corresponding to 4 at.\% $\mathrm{Al}$ on the thin film spread is marked in Fig. 1(b)). The formation of the BCC phase was previously reported for $\mathrm{Al}$ concentrations ranging from 14 to 26 at. $\%$ in the $\mathrm{FeMnCoCr}$ system ${ }^{20}$. The BCC phase becomes more pronounced at the expense of $\alpha-\mathrm{Mn}$ phase as the $\mathrm{Al}$ concentration is increased to 6 at. $\%$. The thin film with 8 at. $\% \mathrm{Al}$, forms a single BCC random solid solution with a lattice parameter of $2.88 \AA$. Al additions cause an increase in the lattice parameter. For example the film containing 20 at.\% of $\mathrm{Al}$ exhibits a $0.35 \%$ increase in the lattice parameter compared to the film containing 8 at.\% of Al. A further increase in $\mathrm{Al}$ concentration to 38 at \% increases the lattice parameter by $1.04 \%$ compared to the film containing 8 at.\% of Al. Furthermore, for the 40 at.\% Al thin film, an additional superlattice peak corresponding to ordered BCC (B2) is observed at $2 \theta=35.7^{\circ}$. Ordering has also been reported upon $\mathrm{Al}$ addition to $\mathrm{CoCrFeNi}$ and FeCoNiCrMn based bulk HEAs ${ }^{23-25}$, where a sole (100) superlattice reflection ${ }^{24,25}$ in addition to the BCC reflections was observed. However, in the present study, thin films with $\mathrm{Al}$ concentrations $<40$ at. $\%$ did not show evidence for the formation of the ordered B2 phase. It should also be noted that the thin film synthesis involves high quenching rates ${ }^{26}$, thus the composition boundaries for phase formation established here might deviate to those obtained by near-equilibrium processing. However, the observed phase formation sequence is of relevance.

As the $\mathrm{Al}$ concentration is increased to 50 at.\% and 54 at.\% the thin films display broader, low intensity peaks, indicating diminishing crystallinity (Fig. 1(c)). This may be due to the increase in the Al content which has a $\sim 15 \%$ larger atomic radius than the average radius of the other alloy constituents. The atomic size difference $(\delta)^{27}$ of the thin film containing $>50$ at. $\% \mathrm{Al}$ is $>6.3 \%$ calculated according to which was reported to result in the formation of metallic glasses ${ }^{27}$.

The local chemical composition of (selected) FeMnCoCrAl thin films is probed by atom probe tomography (APT). Atomic scale elemental distributions of the 8 at.\% $\mathrm{Al}$ thin film, which crystallizes as a single BCC solid solution (based on XRD), are shown in Fig. 2(a). No evidence of precipitation, elemental segregation or phase separation can be observed. The $1 \mathrm{D}$ concentration profiles taken along a $10 \mathrm{~nm}$ diameter cylinder displayed in Fig. 2(b) indicates a uniform distribution. In Fig. 2(c) the frequency distribution analysis ${ }^{28}$ of the entire analyzed volume indicates the formation of a random solid solution. Similarly, the equiatomic $\mathrm{FeMnCoCrAl}(20$ at. $\% \mathrm{Al})$ thin film exhibits a homogeneous distribution of all the elements, as reported previously ${ }^{20}$. However, for the thin film containing 26 at.\% of $\mathrm{Al}$ (Fig. 3(a,b)) a nanoscale (anticorrelated) separation is observed between the 
(a)

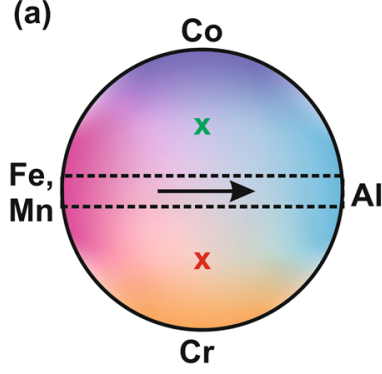

(b)

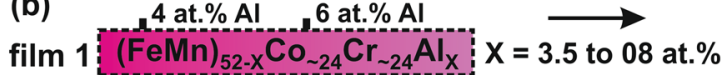

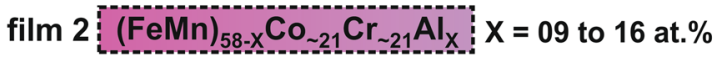

Al film 3 (FeMn) ${ }_{60} \mathrm{Co}_{20} \mathrm{Cr}_{20} \mathrm{Al} \mathrm{I}_{\mathrm{X}} \mathrm{X}=17$ to 26 at.\%

film 4 (FeMn $)_{68-\mathrm{Co}_{16} \mathrm{Cr}_{-16} \mathrm{Al}} \mathrm{X}=27$ to 42 at.\%

film 5 (FeMn $)_{74 . C_{213} \mathrm{Cr}_{13} \mathrm{Al}} \mathrm{X}=43$ to 54 at.\%

$\mathrm{Fe}, \mathrm{Mn}$ rich
Al rich

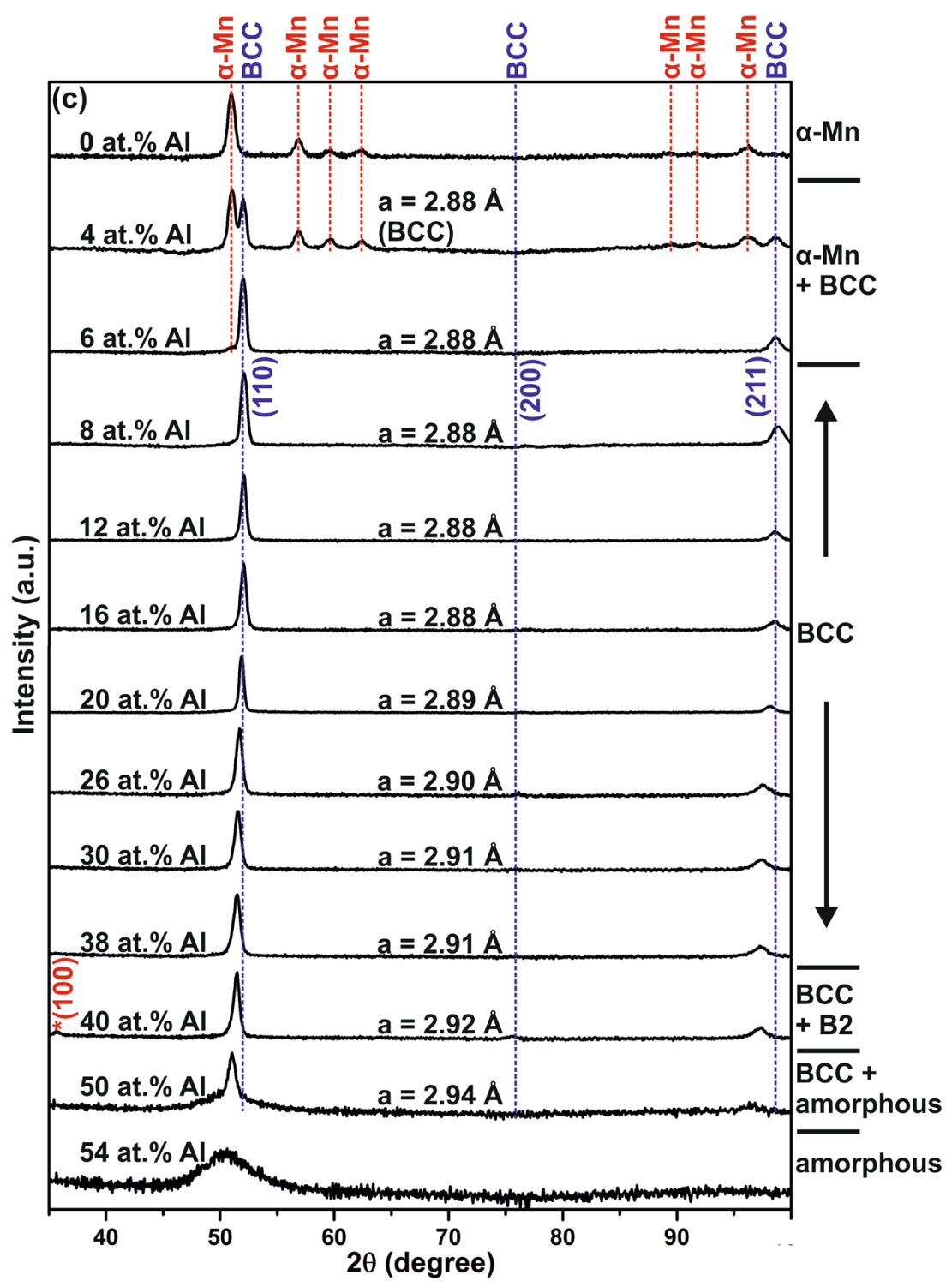

Figure 1. (a) Schematic representation of the combinatorial thin film composition spreads (the dotted box indicate the $\mathrm{Al}$ gradients and the crosses in the figure corresponds to the characterization regions referred to in Fig. 5), (b) Al concentration gradients from five different composition spreads (the markings on film 1 indicate the characterization regions corresponding to 4 and 6 at.\% $\mathrm{Al}$ ) and (c) XRD patterns of the as deposited FeMnCoCrAl thin films (the * in the 40 at.\% Al diffractogram, is to indicate the (100) B2 reflection).

$\mathrm{Al}-\mathrm{Co}$ and $\mathrm{Fe}-\mathrm{Mn}-\mathrm{Cr}$ species. The formation of an $\mathrm{Al}$ rich region with $\mathrm{AlCo} / \mathrm{FeMnCr}$ ratio of 1.4 is observed. The APT results of 40 at. $\% \mathrm{Al} \mathrm{HEA}$, with superlattice peaks at $2 \theta=35.7^{\circ}$, corresponding to a $\mathrm{B} 2$ ordered phase in XRD (Fig. 1(c)), likewise reveal a clear nano-scale ( $\sim 6 \mathrm{~nm}$ width) separated region (Fig. 3 (c,d)). An $\mathrm{Al}_{2.75} \mathrm{Co}$ based $\mathrm{Al}$ rich region exhibiting an $\mathrm{AlCo} / \mathrm{FeMnCr}$ ratio of 3.0 is observed, which is higher than in the 26 at. $\% \mathrm{Al}$ 
(a) Overall
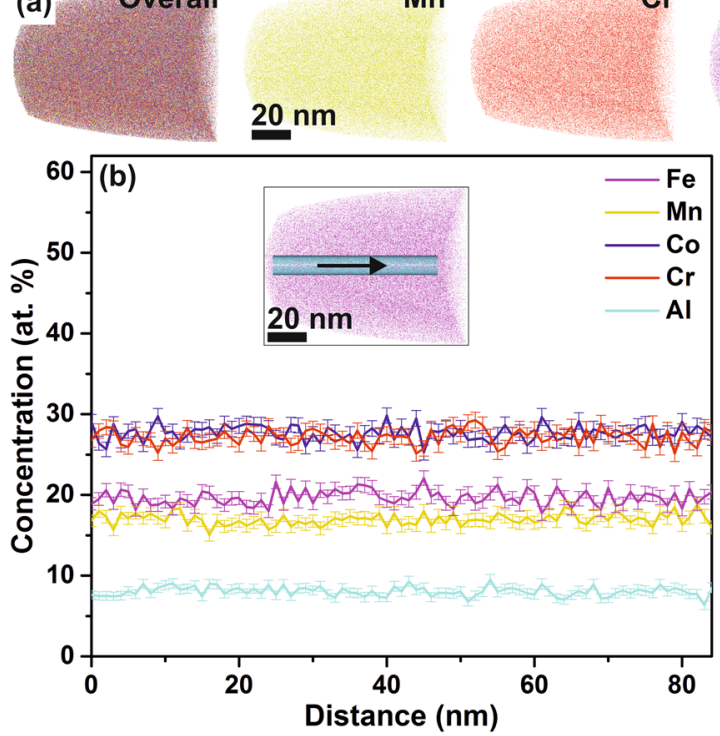

$\mathrm{Mn}$

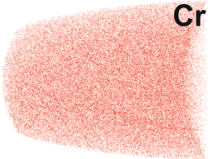

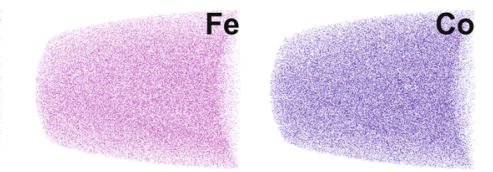

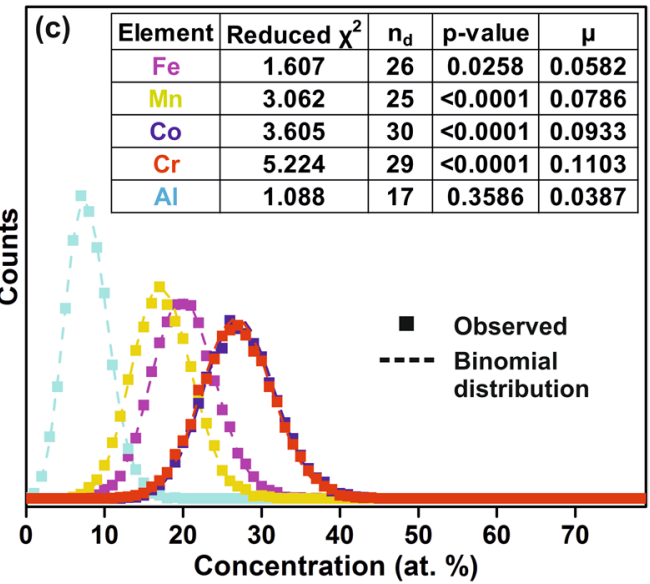

Figure 2. APT (a) elemental distribution, (b) $1 \mathrm{D}$ concentration profile with $1 \mathrm{~nm}$ bin width from the $10 \mathrm{~nm}$ diameter cylindrical region of interest (shown in inset) and (c) frequency distribution analysis (with 100 atoms per bin) of the 8 at.\% Al thin film. $\chi^{2}, n_{d}, p$-value and $\mu$ in the inset table designate the deviation of the experimentally observed distribution to the theoretical binomial random distribution. $\mu$ as a normalized autocorrelation parameter of $\chi^{2}$ can take values between 0 and 1 (where, 0 represents complete randomness and 1 represents clustering).
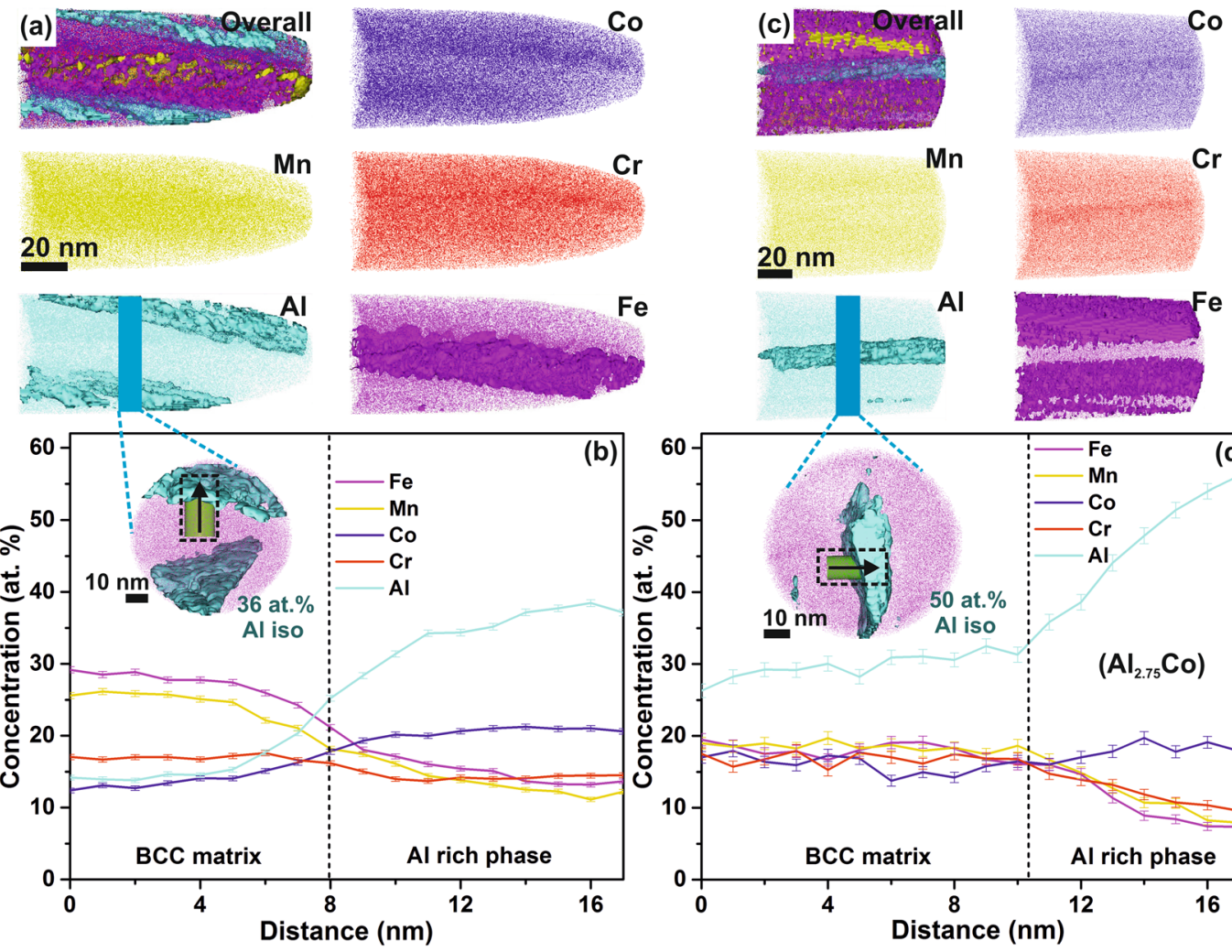

Mn

$\mathrm{Cr}$

$20 \mathrm{~nm}$

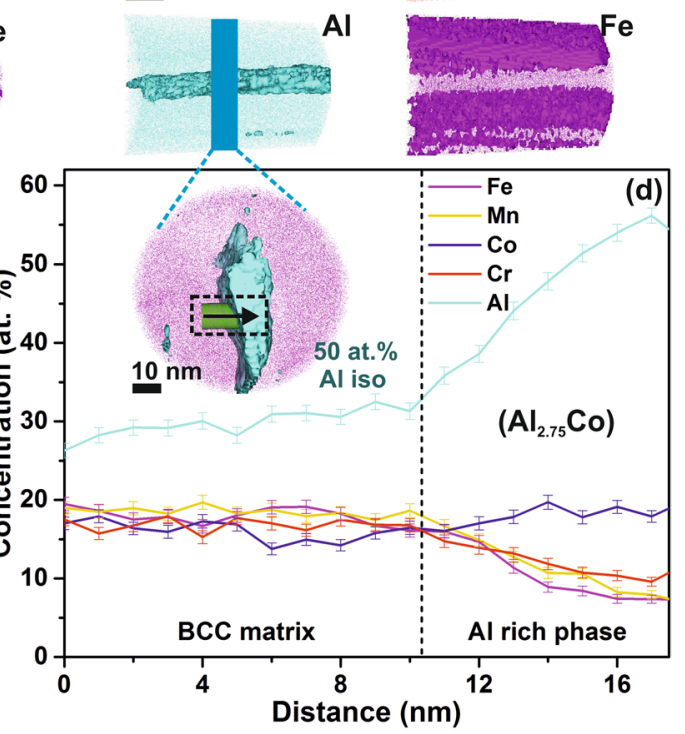

Figure 3. APT elemental distribution (with overlaid iso-concentration surfaces of $\mathrm{Fe}, \mathrm{Mn}$ and $\mathrm{Al}$ ) of the (a) 26 at.\% and (c) 40 at.\% Al thin film, and $1 \mathrm{D}$ concentration profile (with $1 \mathrm{~nm}$ bin width) obtained using a $10 \mathrm{~nm}$ diameter cylindrical region of interest across the $\mathrm{Al}$ rich region of the (b) 26 at.\% and (d) 40 at.\% $\mathrm{Al}$ thin film (inset in $\mathbf{b}$ and $\mathbf{d}$ : $\mathrm{Al}$ iso-concentration surfaces overlaid on Fe distribution). 
thin film with a ratio of 1.4, see Fig. 3(a,b). The enrichment of Al-Co may be accredited to the negative enthalpy of mixing between these constituents. Similar AlCo rich chemical separations with an ordered BCC structure have been reported in a recent transmission electron microscope (TEM) investigation on FeCoCrMnAl single crystals $^{29}$, supporting the notion that the $\mathrm{B} 2$ phase corresponds to the $\mathrm{Al}$ rich region in high $\mathrm{Al}$ containing thin films (Fig. 1 (c)). Even though the FeMnCoCrAl thin films stabilize as a single disordered BCC solid solution at 8 at.\% Al (Fig. 1(c)), nanoscale chemical separation (possibly of similar crystal structure and lattice parameter) is observed for 26 at.\% of incorporated $\mathrm{Al}$ and is not resolved by standard XRD technique (Fig. 1(c)). It is reasonable to assume that the presence of these segregations affect the film properties.

Magnetic property dependence on chemical composition and microstructure. The room temperature magnetic hysteresis behavior of the $\mathrm{FeMnCoCrAl}$ thin films containing various $\mathrm{Al}$ concentrations shown in Fig. 4(a). The FeMnCoCr thin film (without Al) is paramagnetic. As discussed above, a BCC phase is formed upon $\mathrm{Al}$ addition, see Fig. 1(c), concomitantly a ferromagnetic state is induced.

The here observed magnetic behavior corresponds to a soft ferromagnet with a $\mathrm{H}_{\mathrm{c}}$ of $<15 \mathrm{mT}$. The $\mathrm{M}_{\mathrm{s}}$ and $\mathrm{H}_{\mathrm{c}}$ as a function of $\mathrm{Al}$ concentration is displayed in Fig. 4(b). Thin films containing 4 and 6 at. $\%$ of Al exhibit in addition to the $\alpha-\mathrm{Mn}$ structure also the BCC phase. The increase in $\mathrm{M}_{\mathrm{s}}$ from 51 to $80 \mathrm{Am}^{2} / \mathrm{kg}$ is ascribed to the increasing volume fraction of the ferromagnetic BCC phase (see Fig. 1(c)). The largest $\mathrm{M}_{\mathrm{s}}\left(82 \mathrm{Am}^{2} / \mathrm{kg}\right.$ ) is obtained for the single random BCC solid solution (Fig. 1(c)) containing 8 at.\% of Al. A further increase in Al concentration results in a continuous decrease of $\mathrm{M}_{\mathrm{s}}$, so that the equiatomic BCC thin film (20 at.\% Al) possesses a $\mathrm{M}_{\mathrm{s}}$ of 37 $\mathrm{Am}^{2} / \mathrm{kg}$, while the 30 at. $\% \mathrm{Al}$ thin film saturates at $17 \mathrm{Am}^{2} / \mathrm{kg}$.

The decrease in $\mathrm{M}_{\mathrm{s}}$ observed for the BCC HEAs with increasing Al content can be explained, firstly, by considering the magnetic behavior of the constituent elements. Al being paramagnetic, substitutes ferromagnetic species, thus causing a reduction in the number density and hence dilution of ferromagnetic species and consequently a decrease of the overall $\mathrm{M}_{\mathrm{s}}$. Furthermore, since $\mathrm{Al}$ has a $\sim 15 \%$ larger atomic radius than the other constituent elements causing $>6.3 \%$ atomic size difference $(\delta)^{27}$, an increase in the Al concentration causes an increase in lattice parameter (as observed in (Fig. 1(c)) and hence, in unit cell volume. It is reasonable to assume that these distortions contribute together with the above discussed dilution of ferromagnetic species by $\mathrm{Al}$ to the experimentally observed reduction in overall $\mathrm{M}_{\mathrm{s}}$.

The thin film containing 40 at.\% of $\mathrm{Al}$ is weakly ferromagnetic, and exhibits with $7 \mathrm{Am}^{2} / \mathrm{kg}$ the lowest $\mathrm{M}_{\mathrm{s}}$. Addition of $\mathrm{Al}$ to $\mathrm{AlCoCrFeNi}{ }^{11,25,30}$ and $\mathrm{FeCoNiCrMnAl}{ }^{24}$ was reported to promote ordering. AlNi enriched phase separation and ordering was reported to decrease the overall moment of the alloy ${ }^{11}$. Al being paramagnetic has a near zero local moment, thereby reduces the ferromagnetic exchange interaction between the ferromagnetic species. Similar Al enriched phase separated regions are observed by the APT investigations of the films containing 26 and 40 at.\% of $\mathrm{Al}$ (Fig. 3), which is also consistent with the observation of reduced $\mathrm{M}_{\mathrm{s}}$ compared to the single BCC phase region (Fig. 4(b)).

To ascertain the effect of an increased concentration of $\mathrm{Co}$ and $\mathrm{Cr}$ on the $\mathrm{M}_{\mathrm{s}}$, complementary magnetic hysteresis loops were measured for samples containing 8 at $\%$ of $\mathrm{Al}$ with a composition of $\sim \mathrm{Fe}_{22} \mathrm{Mn}_{22} \mathrm{Co}_{27} \mathrm{Cr}_{21} \mathrm{Al}_{8}$ and $\sim \mathrm{Fe}_{22} \mathrm{Mn}_{22} \mathrm{Co}_{21} \mathrm{Cr}_{27} \mathrm{Al}_{8}$ (see Fig. 1(a), where the $\mathrm{Co}$ and $\mathrm{Cr}$ rich regions on the combinatorial thin film schematic are indicated). The phase formation and lattice parameter of the $\mathrm{Co}$ and $\mathrm{Cr}$ rich regions (Fig. 5(a)) are identical to 8 at.\% $\mathrm{Al}$ thin film with a Co/Cr ratio of $1.0 \pm 0.1$ (Fig. 1(c)), whereas a considerable difference is observed for the $M_{s}$ (Fig. 5(b)). The Co rich thin film is characterized by a $21 \%$ increased $M_{s}\left(99 \mathrm{Am}^{2} / \mathrm{kg}\right)$, while the thin film enriched with antiferromagnetic Cr possesses $46 \%$ smaller $\mathrm{M}_{\mathrm{s}}\left(44 \mathrm{Am}^{2} / \mathrm{kg}\right)$ than the 8 at.\% Al thin film with a Co/ Cr ratio of $1.0 \pm 0.1$, which saturates at $82 \mathrm{Am}^{2} / \mathrm{kg}$.

A low $\mathrm{H}_{\mathrm{c}}$ value is another prerequisite for soft magnets and the $\mathrm{H}_{\mathrm{c}}$ of soft magnets is strongly dependent on the grain $\operatorname{size}^{17}$ and the defect structure. The 4 at. $\% \mathrm{Al}$ thin film with both paramagnetic $\alpha-\mathrm{Mn}$ and ferromagnetic BCC phase (see Figs 1(c) and 4(b)) exhibits the highest Hc of $13 \mathrm{mT}$. The FeMnCoCrAl thin films exhibit columnar grain morphologies (Fig. 6), and the average column width of the thin films as a function of Al concentration is correlated with the measured coercivities. TEM bright field images of the thin film cross section are presented in Fig. 6(a-e). Figure 6(f) shows the column width of various thin films as a function of the Al concentration. As the Al concentration is increased, the column width is decreased. The 8 at. $\% \mathrm{Al}$ thin film has a column width of $\sim 54 \mathrm{~nm}$, while the 40 at. $\% \mathrm{Al}$ thin film exhibited the smallest column width of $\sim 20 \mathrm{~nm}$. The corresponding coercivities of the 8 and 40 at.\% Al HEAs were 6.3 and $2.1 \mathrm{mT}$, respectively. The $\mathrm{Al}$ concentration induced decrease in the column width of $63 \%$ results in a $67 \%$ decrease in the coercivity. It should be noted that the coercivity change in the present study is a consequence of both composition and grain size variation. More detailed investigations on factors affecting $\mathrm{H}_{\mathrm{c}}$ and the effects of magnetic anisotropy are subject of future work.

The magnetization of FeMnCoCrAl equiatomic bulk HEA crystallizing according to XRD in the BCC structure $^{20}$, is compared to the near equiatomic FeMnCoCrAl thin film in Fig. 4. While the FeMnCoCr bulk HEA without $\mathrm{Al}$ additions is paramagnetic, the $\mathrm{BCC}$ bulk FeMnCoCrAl HEA ${ }^{20}$ is (soft) ferromagnetic (Fig. 4(a), dotted curve). The $\mathrm{M}_{\mathrm{s}}$ and $\mathrm{H}_{\mathrm{c}}$ of the bulk HEA are $49 \mathrm{Am}^{2} / \mathrm{kg}$ and $1.4 \mathrm{mT}$, respectively (Fig. 4(b)), while the equiatomic FeMnCoCrAl thin film saturated at $37 \mathrm{Am}^{2} / \mathrm{kg}$ with a $\mathrm{H}_{\mathrm{c}}$ of $3.5 \mathrm{mT}$. The $\mathrm{M}_{\mathrm{s}}$ of the thin film is $24 \%$ smaller than its bulk counterpart. This difference may at least in part be attributed to the magnetic anisotropy of textured thin films with columnar morphology ${ }^{31}$. On the other hand, the coercivity of the thin film is 2.5 times larger than the bulk, most likely due to the different microstructures. The bulk HEAs exhibit equiaxed, $\mu \mathrm{m}$ sized grains ${ }^{20}$, while the thin film morphology is clearly columnar.

Electronic structure of FeMnCoCrAI HEA. Ab initio density functional theory (DFT) calculations were performed to investigate the influence of the Al concentration on the phase stability of BCC and FCC phases as well as the magnetic behavior. The magnetic moments were determined within the Exact muffin tin orbitals (EMTO) formalism (as described in the methods section) and the variation of total magnetic moment with 

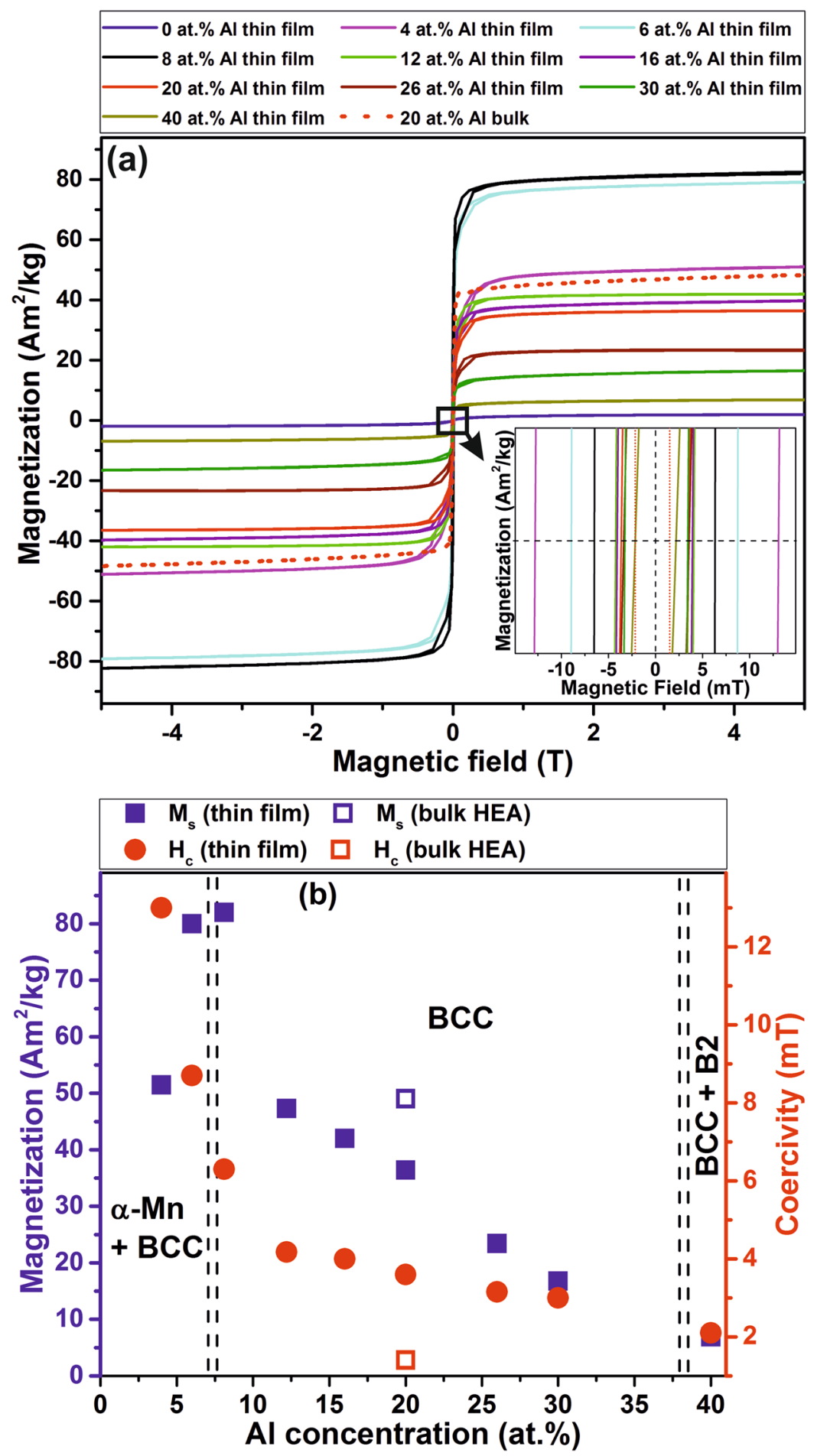

Figure 4. (a) Magnetization vs. magnetic field at room temperature for different thin film HEAs, and (b) $\mathrm{M}_{\mathrm{s}}$ and $\mathrm{H}_{\mathrm{c}}$ variation as a function of $\mathrm{Al}$ concentration. The dashed line indicates the composition boundary between multi and single phase thin films.

varying $\mathrm{Al}$ concentration is compared with previously reported internal energy difference $\left(\Delta \mathrm{E}_{\mathrm{BCC}-\mathrm{FCC}}\right)$ data between the BCC and FCC structures ${ }^{20}$, as displayed in Fig. 7(a).

The phase stability data $\left(\triangle \mathrm{E}_{\mathrm{BCC}-\mathrm{FCC}}\right)$ for the FeMnCoCrAl system were calculated only for the BCC and FCC structures, as these are the crystal structures observed in $3 \mathrm{~d}$ transition metal based $\mathrm{HEAs}^{27}$. The FeMnCoCr configuration is stable in the paramagnetic (PM) FCC structure, whereas for the Al containing FeMnCoCrAl configurations, the ferromagnetic (FM) BCC structure (Fig. 7(a)) is the stable configuration, and in good agreement with the here presented experimental results (Fig. 1(c)). The BCC phase stability exhibits a slightly decreasing trend when the $\mathrm{Al}$ content is increased. 

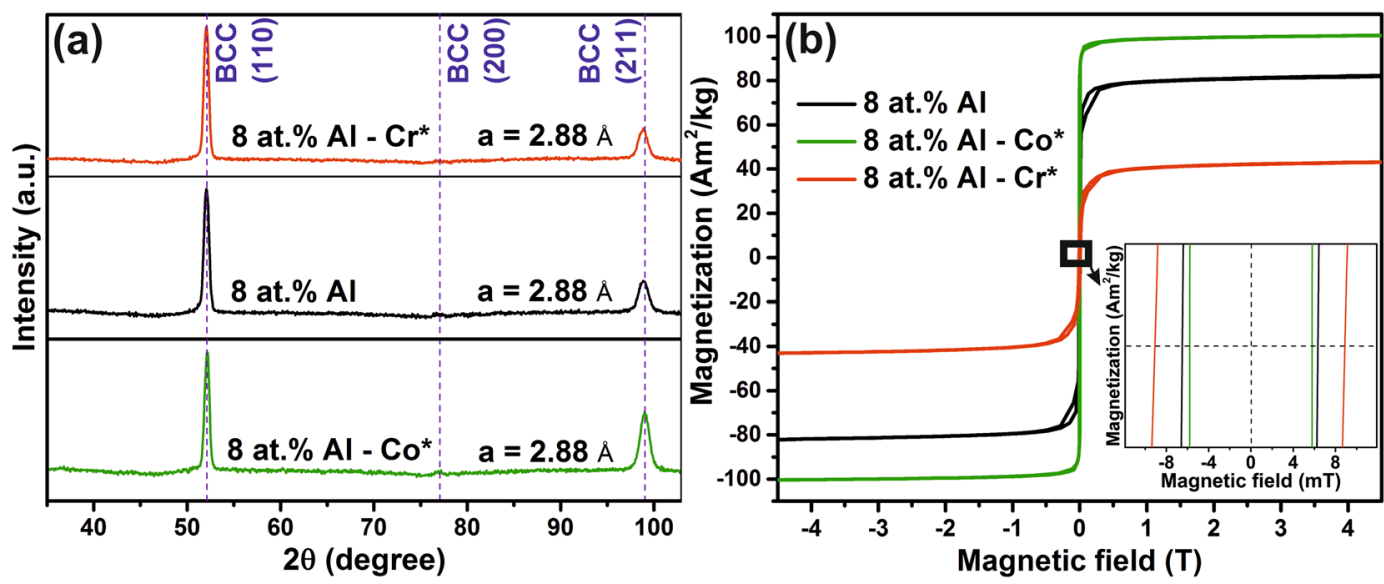

Figure 5. (a) XRD patterns and (b) room temperature magnetization vs. magnetic field curves of the 8 at. $\% \mathrm{Al}$ (described in Fig. 1c), 8 at.\% $\mathrm{Al}-\mathrm{Co}$ rich $(\mathrm{Co} *)$ and $\mathrm{Cr}$ rich $\left(\mathrm{Cr}^{*}\right)$ thin films.
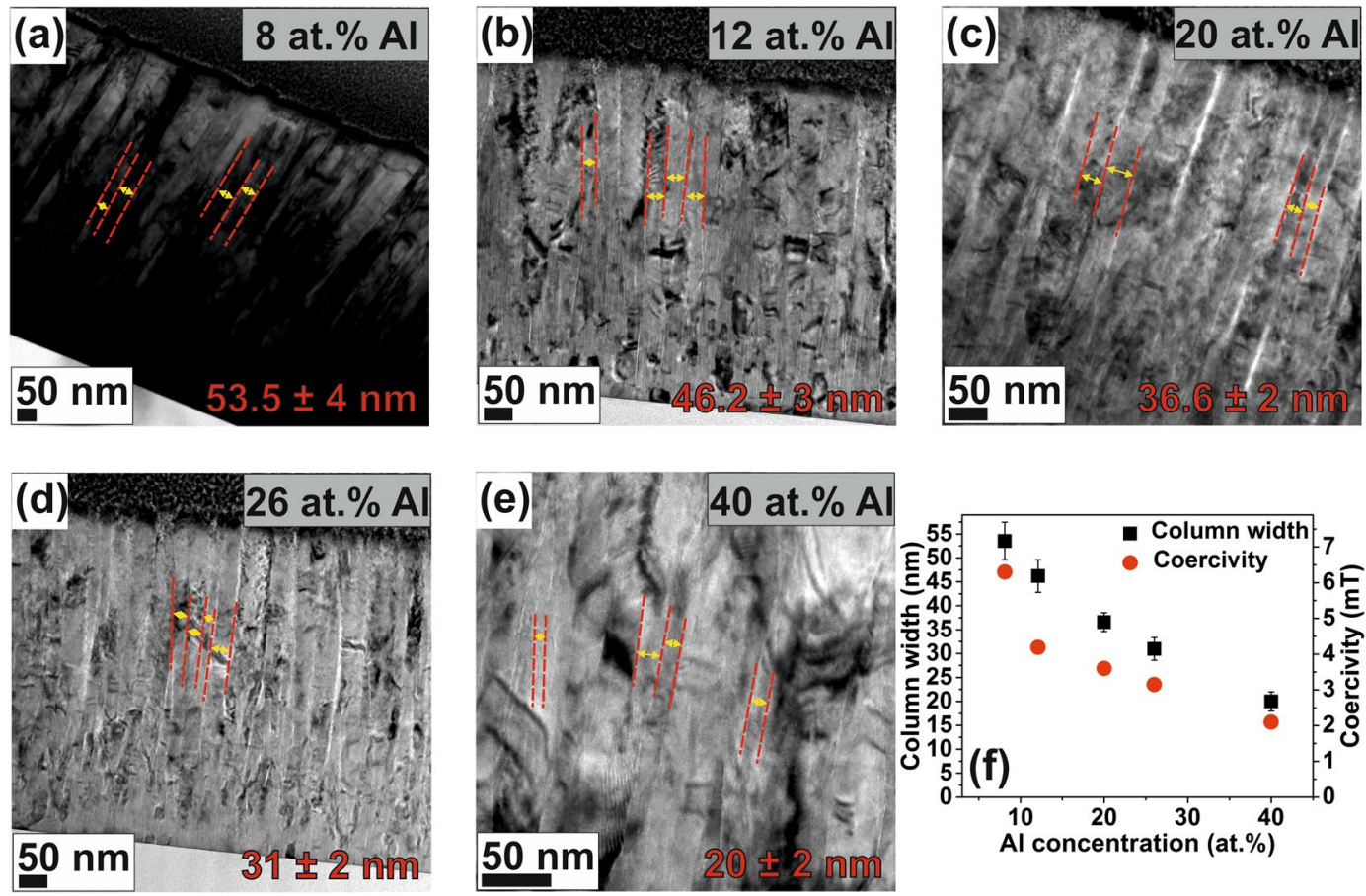

Figure 6. (a-e) TEM bright-field images showing columnar grain morphology (line markings overlaid to indicate the column width), and (f) column width dependence of the room temperature $\mathrm{H}_{\mathrm{c}}$ for $\mathrm{FeMnCoCrAl}$ thin films with varying $\mathrm{Al}$ concentration.

The total magnetic moment of the BCC FeMnCoCrAl configuration is shown in Fig. 7(a). Regarding the local moment of the individual elements, $\mathrm{Fe}, \mathrm{Mn}$ and Co possess positive, $\mathrm{Cr}$ exhibits negative (antiparallel) and $\mathrm{Al}$ has near zero magnetic moment, as in their ground states. The calculated magnetic moment (for the experimentally obtained single phase region) is highest for the BCC configuration containing 8 at.\% Al. Further Al addition to the system (>8 at.\%) leads to a decrease in the magnetic moment, and an increase in the unit cell volume (as reflected from the calculated lattice parameter results in Fig. 7(a)), likely diluting and weakening the ferromagnetic exchange interactions. As expected, the magnitude of the calculated $0 \mathrm{~K}$ DFT total magnetic moment values are higher than that of the $300 \mathrm{~K}$ experimental data ${ }^{32}$. Nevertheless, the trend of the calculated moment vs $\mathrm{Al}$ concentration is consistent with the experimental data. Magnetic moments were also calculated for the 8 at. $\% \mathrm{Al}$ content of the $\mathrm{Co}$ and $\mathrm{Cr}$ rich compositions described in the previous section (see Fig. 5). Also, the trend in total moment values for both $\mathrm{Cr}$ rich and Co rich compositions are consistent with the experimental observations: An increase in antiferromagnetic $\mathrm{Cr}$ content decreases the overall magnetic moment, while Co additions result in an increase compared to the 8 at.\% $\mathrm{Al}$ thin film with a $\mathrm{Cr} / \mathrm{Co}$ ratio of $1.0 \pm 0.1$. To elucidate the role of electronic structure on ferromagnetism, spin polarized density of states (DOS) data are presented in Fig. $7\left(\mathrm{~b}_{1,2}\right)$. The total 

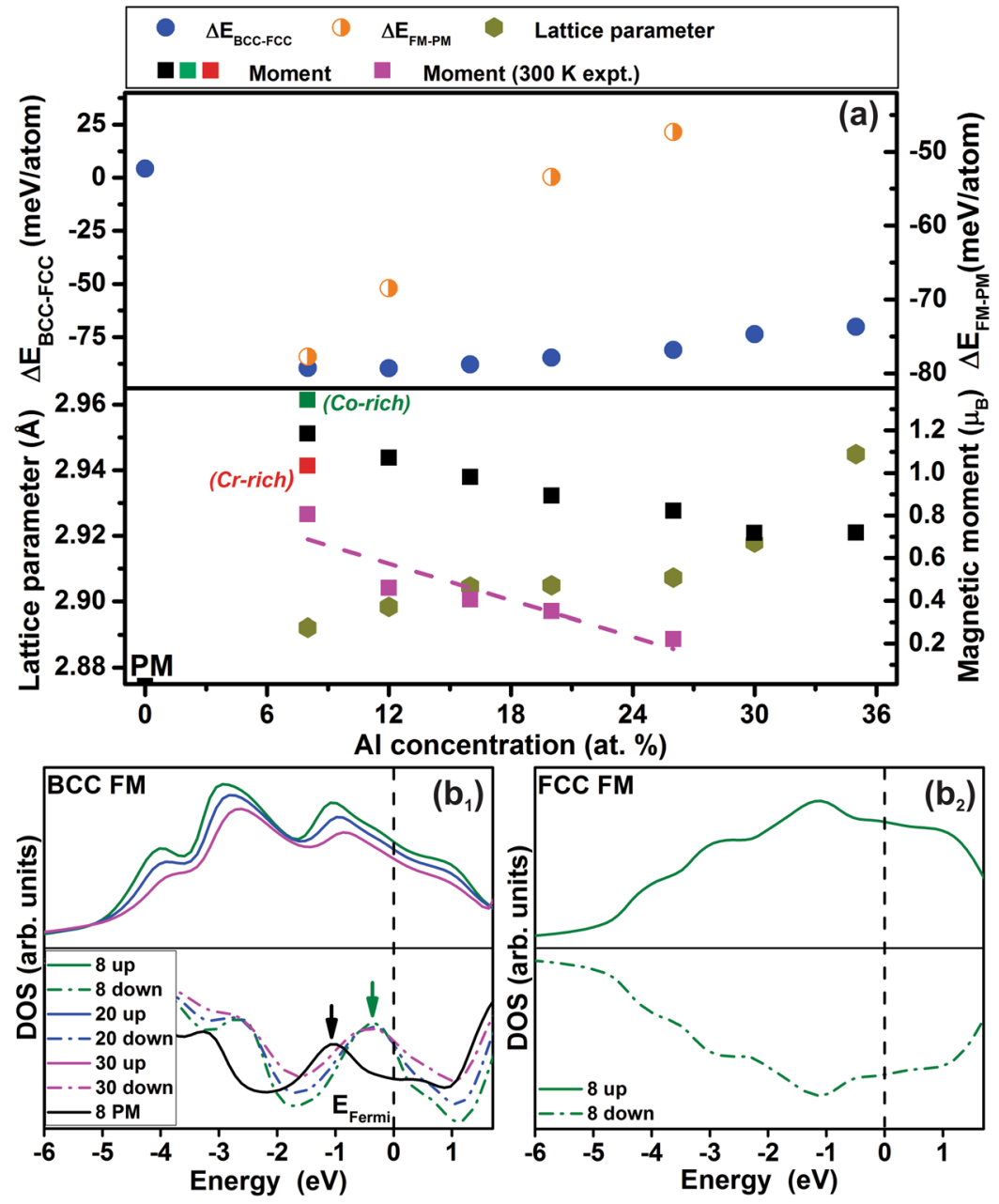

Figure 7. DFT calculations: (a) Internal energy difference $(\Delta \mathrm{E})$, lattice parameter and total magnetic moment of BCC HEAs with varying Al concentrations, and $\left(\mathbf{b}_{1,2}\right)$ spin polarized total DOS for 8 at.\% $\mathrm{Al} \mathrm{HEA}$ in BCC and FCC structure. The Fermi level is set to $0 \mathrm{eV}$. The arrows in $\left(\mathbf{b}_{1}\right)$ indicate the pseudogap position of BCC FM (green) with respect to the BCC PM (black) configuration.

density of states was evaluated for two different spin polarized equilibrium configurations, namely (i) the BCC and (ii) the FCC state. The electronic structure analysis of the random BCC configuration containing 8 at.\% of $\mathrm{Al}$ in terms of up and down spin states is shown in Fig. $7\left(\mathrm{~b}_{1,2}\right)$. The distribution of both up and down spin states is clearly asymmetric (Fig. 7( $\left.\mathrm{b}_{1}\right)$ ), indicating ferromagnetism. Conversely, the FCC structure displays a symmetric up and down spin states (Fig. $7\left(b_{2}\right)$ ), suggesting magnetization cancellation. Furthermore, ferromagnetism in the BCC configuration decreases the number of states by pseudogap formation at the Fermi level with respect to the paramagnetic state, as indicated by green and black arrows in Fig. $7\left(b_{1}\right)$, and thereby stabilizes the system. This argumentation is based on the notion that if a Fermi level is located in a pseudogap, separating bonding and antibonding states, the alloy is stabilized ${ }^{33}$.

Curie temperature and electrical resistivity of FeMnCoCrAl thin films. Magnetic transitions determine the operating temperature ranges of ferromagnets. The temperature dependence of magnetization for the thin films is shown in Fig. 8(a). The 8 at.\% Al single BCC phase (Fig. 1(c)) thin film possesses the highest $\mathrm{T}_{\mathrm{c}}>900 \mathrm{~K}$ (which is beyond our measurement limit), making these alloys viable candidates for applications of soft magnetic materials at high operation temperatures.

A decreasing trend is observed in $\mathrm{T}_{c}$ with an increase in the $\mathrm{Al}$ concentration, where the 12 at. $\% \mathrm{Al}$ and equiatomic 20 at. $\% \mathrm{Al}$ thin film showed a $\mathrm{T}_{\mathrm{c}}$ of $\sim 850 \mathrm{~K}$ and of $700 \mathrm{~K}$, respectively, while the high $\mathrm{Al}$ containing 26 at. $\%$ $\mathrm{Al}$ thin film exhibits the lowest magnetic transition temperature at $\sim 600 \mathrm{~K}$. The observed decrease in $\mathrm{T}_{c}$ with increasing $\mathrm{Al}$ content can be rationalized based on the internal energy difference between the ferromagnetic and paramagnetic $\mathrm{BCC}$ FeMnCoCrAl configurations. The magnetic transition from ferromagnetic to paramagnetic state occurs at the $\mathrm{T}_{\mathrm{c}}$ and the energy difference (Fig. 7(a), $\Delta \mathrm{E}_{\mathrm{FM}-\mathrm{PM}}$ ) between the two states gives an indication about the transition temperature. The energy difference is maximized for the 8 at.\% Al alloy with a highest $\mathrm{T}_{\mathrm{c}}$ and decreases with increasing $\mathrm{Al}$ content. The 26 at.\% Al HEA exhibits the minimum energy difference and hence a lower $\mathrm{T}_{c}$. The observed inverse relationship between $\mathrm{T}_{\mathrm{c}}$ and the $\mathrm{Al}$ concentration can also be rationalized by considering the paramagnetic nature of $\mathrm{Al}$. We have demonstrated that the $\mathrm{Al}$ concentration induced reduction in $\mathrm{T}_{c}$ 

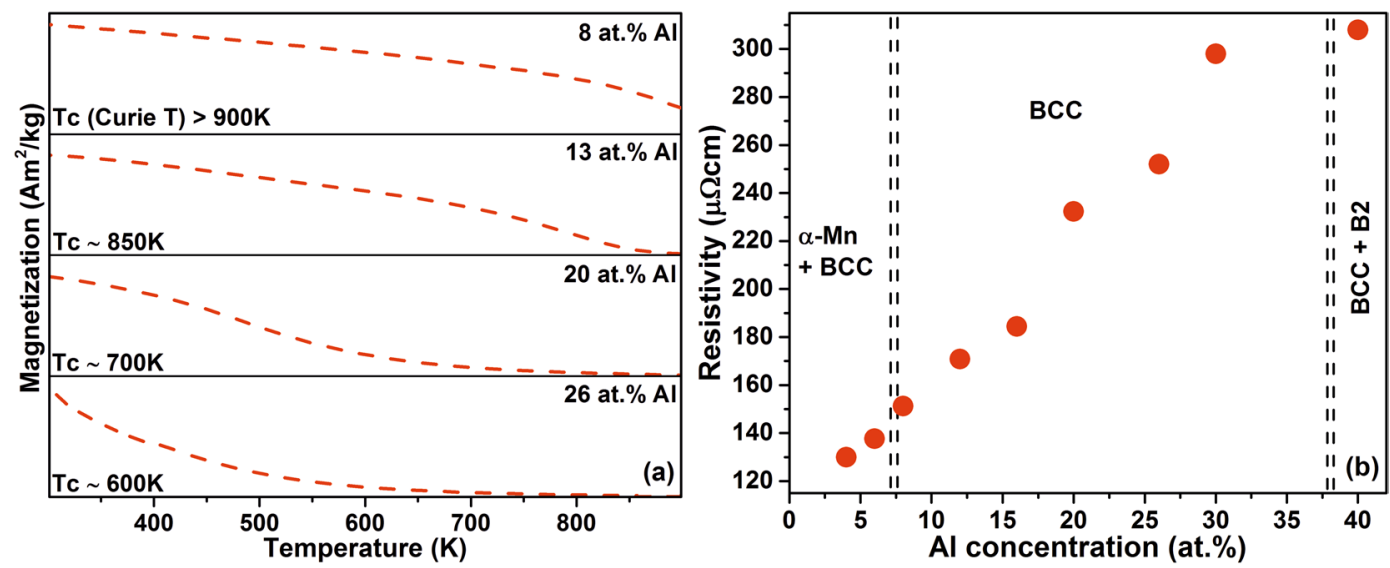

Figure 8. (a) Temperature dependence of magnetization at $10 \mathrm{mT}$ applied field, and (b) room temperature electrical resistivities of selected thin films with varying $\mathrm{Al}$ concentrations. The dashed line indicates the composition boundary between multi and single phase thin films.

without compromising phase stability may enable application of this material system in magneto-caloric devices where Curie temperatures near room temperature are required, as well as in applications requiring high Curie temperatures like power transformers and high frequency inductors.

Large electrical resistivity is another desired property of soft magnetic materials to minimize eddy current losses ${ }^{14,17}$. The sheet resistivity of the thin films with varying $\mathrm{Al}$ concentration was measured at room temperature (Fig. 8(b)). The thin film HEAs exhibit large resistivity values $(>130 \mu \Omega \mathrm{cm})$, when compared to conventional soft magnets ${ }^{17}$. The single phase BCC films containing 8 at. $\%$ of Al exhibits a resistivity of $151 \mu \Omega \mathrm{cm}$, and the resistivity increases as the $\mathrm{Al}$ concentration is increased. The addition of large atomic radius $\mathrm{Al}$ to the system causes large lattice distortions (as seen in the XRD results) in addition to the inherent topological distortion and chemical randomness in the HEAs ${ }^{14}$. These distortions were reported to cause more electron scattering and hence higher electrical resistivities are observed ${ }^{14}$. From microstructure point of view, the grain size and fraction of grain boundaries also influence the electrical resistivity. As the concentration of $\mathrm{Al}$ increases the nano-column width (Fig. 6) of the FeMnCoCrAl thin films decreases, thereby increasing the fraction of grain boundaries causing a concomitant increase in the sheet resistivities of the thin films. Furthermore, in terms of electronic structure the configurations containing 8 at.\% of $\mathrm{Al}$ exhibit a larger number of states (Fig. $7\left(\mathrm{~b}_{1}\right)$ ) at the Fermi level, rendering the materials with a lower intrinsic resistivity than configurations with larger $\mathrm{Al}$ concentrations.

\section{Conclusions}

The effect of Al content (3.5-54 at.\%) on phase formation and magnetic properties of combinatorially deposited FeMnCoCrAl thin films has been investigated systematically by using conventional and spatially resolved characterization techniques as well as DFT. Al additions to the FeMnCoCr crystallizing in the $\alpha$-Mn structure cause the formation of a BCC phase. Thin films containing 8 at. $\%$ of $\mathrm{Al}$ exhibit a single phase BCC structure and atom probe tomography revealed that the solid solution identified by XRD is in fact disordered. However, thin films containing 26 at.\% of Al contain only the BCC phase as identified using XRD showed clear evidence for the presence of Al-Co rich $(\sim 10 \mathrm{~nm})$ nano-scale segregations by atom probe tomography. Similar segregations were also identified for the sample containing 40 at. $\%$ of $\mathrm{Al}$ which exhibited the presence of $\mathrm{B} 2$ type ordering by XRD. DFT predictions on the effect of $\mathrm{Al}$ additions to $\mathrm{FeMnCoCr}$ causing the formation of the BCC phase are consistent with the experimental data. Al additions cause the formation of a pseudogap at the Fermi level rendering the ferromagnetic BCC phase more stable than paramagnetic FCC phase. Magnetometry measurements reveal a paramagnetic behavior in the FeMnCoCr system crystallizing in the $\alpha-\mathrm{Mn}$ structure. Upon $\mathrm{Al}$ addition the BCC structure is formed, exhibiting a (soft) ferromagnetic behavior, where the thin film containing 8 at.\% of Al displays with $82 \mathrm{Am}^{2} / \mathrm{kg}$ the maximum magnetization. Further increase in the non-ferromagnetic Al content beyond 8 at.\% decreases the overall $\mathrm{M}_{\mathrm{s}}$. This can be understood by considering the substitution of ferromagnetic species by paramagnetic $\mathrm{Al}$ as well as by the concomitantly induced lattice distortions. The measured trend of the Al concentration induced reduction in magnetization is consistent with DFT predictions. The here employed experimental and theoretical research strategy was shown to be efficient in explaining the $\mathrm{Al}$ concentration dependent phase formation and magnetic properties, and shows therefore great potential for future design of efficient soft magnetic HEA thin films.

\section{Methods}

Experimental details. Combinatorial FeMnCoCrAl HEA thin films, exhibiting Al concentration gradients were grown on single crystalline $\mathrm{Si}(100)$ and $\mathrm{Al}_{2} \mathrm{O}_{3}$ (0001) (for temperature dependent magnetization studies) substrates. The phase formation behavior was similar on both the substrates. An equiatomic FeMn target (with $\sim 99.95 \%$ purity), as well as elemental $\mathrm{Co}, \mathrm{Cr}$ and $\mathrm{Al}$ targets (with $\sim 99.95 \%$ purity) were employed in a co-sputtering geometry ${ }^{20,34}$ (Fig. 1(a)). A constant power density was applied to the FeMn $\left(7.5 \mathrm{~W} \mathrm{~cm}^{-2}\right)$ and Co, Cr ( $\sim 4 \mathrm{~W} \mathrm{~cm}^{-2}$ each) cathodes, while for the $\mathrm{Al}$ target, the power density was varied from 2 to $7.5 \mathrm{~W} \mathrm{~cm}^{-2}$ to obtain multiple $\mathrm{Al}$ concentration gradients (Fig. 1(b)), which facilitate the efficient investigation of the effect of $\mathrm{Al}$ content on phase formation and magnetic properties. In addition, a four component FeMnCoCr thin film was also 
deposited to study the phase formation in the absence of Al. The base pressure of the system was $2 \times 10^{-5} \mathrm{~Pa}$ and $\operatorname{Ar}(0.4 \mathrm{~Pa})$ gas was used as a sputtering gas. No intentional heating was applied to the substrates during deposition. The deposition was carried out for $22 \mathrm{~min}$, which resulted in a film thickness of $\sim 1 \mu \mathrm{m}$. The deposition geometry and other process specifics of the combinatorial setup are described elsewhere ${ }^{34}$. The substrate temperature before venting was $<80^{\circ} \mathrm{C}$ to minimize the effect of chemical reactions of the film surface with the atmosphere ${ }^{35}$.

The chemical composition of the thin film spreads were quantified using EDX analysis, in a JEOL-JSM-6480 scanning electron microscope (SEM) at an acceleration voltage of $15 \mathrm{kV}$. The phase formation of the thin film composition spreads was determined using XRD, employing a Bruker D8 general area detection diffraction system in grazing incidence geometry $\left(\Omega=10^{\circ}\right)$ with Co K $\alpha$ radiation.

The microstructure of the samples were characterized using a FEI Tecnai F20 TEM ${ }^{36}$ operated at $200 \mathrm{kV}$. Near atomic scale elemental distribution of the FeMnCoCrAl thin films were investigated at $60 \mathrm{~K}$ tip temperature by APT. A Cameca Local Electrode Atom Probe (LEAP) 4000X HR instrument, operated in laser pulse mode, employing a $30 \mathrm{pJ}$ pulse energy at a constant applied frequency of $250 \mathrm{kHz}$ was used. Post measurement data reconstruction and analysis were done using the IVAS 3.6.10a software provided by Cameca Instruments. Samples for both TEM and APT measurements from the thin film spreads were prepared by Ga ion beam milling in a dual beam FEI Helios NanoLab 660 microscope.

The magnetization behavior of the FeMnCoCrAl HEA thin films at various magnetic fields and temperatures were probed using the Vibrating Sample Magnetometer (VSM) option at a Physical Property Measurement System $\left(\mathrm{PPMS}^{\circledR}\right)$ from Quantum Design. A maximum field of $5 \mathrm{~T}$ was applied to saturate the HEA thin films, while the temperature dependent magnetization was studied at a constant applied field of $10 \mathrm{mT}$. Room temperature electrical resistance measurements of the combinatorial thin film library were carried out using a custom built four point probe setup. Current and potential difference measurements were performed using a Keithley digital multimeter $(2611 \mathrm{~B})$ to determine the specific sheet resistivity of the FeMnCoCrAl thin films using the Van-der-Pauw method ${ }^{37}$

Ab initio calculations. Ab initio DFT calculations on the FeMnCoCrAl based system for various $\mathrm{Al}$ concentrations were performed to determine the phase stability, magnetic moments of the corresponding stable states and the spin polarized DOS. EMTO, based on Green's functions and full charge density, as described in ${ }^{20,38,39}$ were utilized. The generalized gradient approximation was applied for the density functionals and ion cores were kept frozen. The integration in the Brillouin zone was carried out on a $13 \times 13 \times 13 \mathrm{k}$-mesh and the total energy convergence criterion was set to $10^{-7} \mathrm{Ry}$. The compositional disorder for HEA was described within the coherent potential approximation (CPA). The CPA derived data have been proven to be consistent with experimental data for multicomponent HEAs ${ }^{40,41}$. The magnetic state of both the BCC and FCC HEA was treated in two ways, the magnetically ordered configurations with ferromagnetic polarization and the magnetically disordered configurations with CPA randomized magnetic moments, which is known as the disordered local moment (DLM) model ${ }^{42}$. This DLM model provides a reasonable approximation of the paramagnetic state above the transition temperature $^{20,43}$. The local magnetic moment of the HEAs was evaluated based on generalized gradient approximation by Perdew-Burke-Ernzerhof ${ }^{44}$.

\section{Data Availability}

The data and samples analyzed during the current study are available from the corresponding author on reasonable request.

\section{References}

1. Yeh, J. W. et al. Nanostructured High-Entropy Alloys with Multiple Principal Elements: Novel Alloy Design Concepts and Outcomes. Advanced Engineering Materials 6, 299 (2004).

2. Miracle, D. B. \& Senkov, O. N. A critical review of high entropy alloys and related concepts. Acta Materialia 122, 448-511 (2017).

3. Li, Z. M., Pradeep, K. G., Deng, Y., Raabe, D. \& Tasan, C. C. Metastable high-entropy dual-phase alloys overcome the strengthductility trade-off. Nature 534, 227 (2016).

4. Gludovatz, B. et al. A fracture-resistant high-entropy alloy for cryogenic applications. Science 345, 1153 (2014).

5. Yao, M. J., Pradeep, K. G., Tasan, C. C. \& Raabe, D. A novel, single phase, non-equiatomic FeMnNiCoCr high-entropy alloy with exceptional phase stability and tensile ductility. Scr. Mater. 72-73, 5 (2014).

6. Wu, Z., Bei, H., Otto, F., Pharr, G. M. \& George, E. P. Recovery, recrystallization, grain growth and phase stability of a family of FCCstructured multi-component equiatomic solid solution alloys. Intermetallics 46, 131 (2014).

7. Pradeep, K. G. et al. Atomic-scale compositional characterization of a nanocrystalline AlCrCuFeNiZn high-entropy alloy using atom probe tomography. Acta Materialia 61, 4696 (2013).

8. Ma, D. et al. Phase stability of non-equiatomic CoCrFeMnNi high entropy alloys. Acta Materialia 98, 288 (2015).

9. Deng, Y. et al. Design of a twinning-induced plasticity high entropy alloy. Acta Materialia 94, 124 (2015).

10. Li, Z., Tasan, C. C., Pradeep, K. G. \& Raabe, D. A TRIP-assisted dual-phase high-entropy alloy: Grain size and phase fraction effects on deformation behavior. Acta Materialia 131, 323 (2017).

11. Kao, Y.-F. et al. Electrical, magnetic, and Hall properties of AlxCoCrFeNi high-entropy alloys. Journal of Alloys and Compounds 509, 1607 (2011).

12. Lucas, M. S. et al. Magnetic and vibrational properties of high-entropy alloys. J. Appl. Phys. 109, 3 (2011).

13. Kormann, F. et al. "Treasure maps" for magnetic high-entropy-alloys from theory and experiment. Applied Physics Letters 107, 142404 (2015).

14. Zhang, Y., Zuo, T. T., Cheng, Y. Q. \& Liaw, P. K. High-entropy Alloys with High Saturation Magnetization, Electrical Resistivity, and Malleability. Scientific Reports 3, 1455 (2013).

15. Schneeweiss, O. et al. Magnetic properties of the CrMnFeCoNi high-entropy alloy. Physical Review B 96, 014437 (2017).

16. Borkar, T. et al. A combinatorial assessment of AlxCrCuFeNi2 $(0<\mathrm{x}<1.5)$ complex concentrated alloys: Microstructure, microhardness, and magnetic properties. Acta Materialia 116, 63 (2016).

17. Herzer, G. Modern soft magnets: Amorphous and nanocrystalline materials. Acta Materialia 61, 718 (2013).

18. Chen, N., Zaefferer, S., Lahn, L., Günther, K. \& Raabe, D. Effects of topology on abnormal grain growth in silicon steel. Acta Materialia 51, 1755 (2003). 
19. Minnert, C. et al. Study on the embrittlement of flash annealed Fe85.2B9.5P4Cu0.8Si0.5 metallic glass ribbons. Materials \& Design 156, 252 (2018).

20. Marshal, A. et al. Combinatorial synthesis of high entropy alloys: Introduction of a novel, single phase, body-centered-cubic FeMnCoCrAl solid solution. Journal of Alloys and Compounds 691, 683 (2017).

21. Gebhardt, T., Music, D., Takahashi, T. \& Schneider, J. M. Combinatorial thin film materials science: From alloy discovery and optimization to alloy design. Thin Solid Films 520, 5491 (2012).

22. Heikes, R. R. Ferromagnetism in Heusler's Alloys. Physical Review 84, 376 (1951).

23. Manzoni, A., Daoud, H., Völkl, R., Glatzel, U. \& Wanderka, N. Phase separation in equiatomic AlCoCrFeNi high-entropy alloy. Ultramicroscopy 132, 212 (2013).

24. He, J. Y. et al. Effects of $\mathrm{Al}$ addition on structural evolution and tensile properties of the FeCoNiCrMn high-entropy alloy system. Acta Materialia 62, 105 (2014).

25. Yang, T. et al. Effects of $\mathrm{Al}$ addition on microstructure and mechanical properties of AlxCoCrFeNi High-entropy alloy. Materials Science and Engineering: A 648, 15 (2015).

26. Schnabel, V. et al. Electronic hybridisation implications for the damage-tolerance of thin film metallic glasses. Scientific Reports 6 , 36556 (2016).

27. Zhang, Y. et al. Microstructures and properties of high-entropy alloys. Progress in Materials Science 61, 1 (2014).

28. Moody, M. P., Stephenson, L. T., Ceguerra, A. V. \& Ringer, S. P. Quantitative binomial distribution analyses of nanoscale like-solute atom clustering and segregation in atom probe tomography data. Microscopy Research and Technique 71, 542 (2008).

29. Feuerbacher, M., Würtz, E., Kovács, A. \& Thomas, C. Single-crystal growth of a FeCoCrMnAl high-entropy alloy. Materials Research Letters 5, 128 (2017).

30. Kao, Y.-F., Chen, T.-J., Chen, S.-K. \& Yeh, J.-W. Microstructure and mechanical property of as-cast, -homogenized, and -deformed AlxCoCrFeNi $(0 \leq \mathrm{x} \leq 2)$ high-entropy alloys. Journal of Alloys and Compounds 488, 57 (2009).

31. Soonchul, J., Yeonbong, C. \& Sanghyun, R. Magnetic anisotropy of sputtered FeN films due to anisotropic columnar growth of grains. IEEE Transactions on Magnetics 33, 3634 (1997).

32. Hostert, C., Music, D., Kapaklis, V., Hjörvarsson, B. \& Schneider, J. M. Density, elastic and magnetic properties of Co-Fe-Ta-Si metallic glasses by theory and experiment. Scr. Mater. 66, 765 (2012).

33. Ravindran, P. \& Asokamani, R. Correlation between electronic structure, mechanical properties and phase stability in intermetallic compounds. Bulletin of Materials Science 20, 613 (1997).

34. Gebhardt, T. et al. Influence of chemical composition and magnetic effects on the elastic properties of fcc Fe-Mn alloys. Acta Materialia 59, 1493 (2011).

35. Greczynski, G., Mráz, S., Hultman, L. \& Schneider, J. M. Venting temperature determines surface chemistry of magnetron sputtered TiN films. Applied Physics Letters 108, 41603 (2016).

36. Ernst Ruska-Centre for Microscopy and Spectroscopy with Electrons. FEI Tecnai G2 F20. Journal of large-scale research facilities 2 , A77, https://doi.org/10.17815/jlsrf-2-138 (2016).

37. Van Der Pauw, L. J. A method of measuring specific resistivity and Hall effect of discs of arbitrary shapes. Philips Research Reports 13, 1 (1958).

38. Vitos, L. Total-energy method based on the exact muffin-tin orbitals theory. Physical Review B 64, 14107 (2001).

39. Vitos, L., Kollár, J. \& Skriver, H. L. Full charge-density scheme with a kinetic-energy correction: Application to ground-state properties of the $4 \mathrm{~d}$ metals. Physical Review B 55, 13521 (1997).

40. Zhang, H. et al. Elastic properties of AlxCrMnFeCoNi $(0 \leq \mathrm{x} \leq 5)$ high-entropy alloys from ab initio theory. Acta Materialia 155, 12 (2018).

41. Sun, X. et al. Phase selection rule for Al-doped CrMnFeCoNi high-entropy alloys from first-principles. Acta Materialia 140, 366 (2017).

42. Staunton, J., Gyorffy, B. L., Pindor, A. J., Stocks, G. M. \& Winter, H. The "disordered local moment" picture of itinerant magnetism at finite temperatures. Journal of Magnetism and Magnetic Materials 45, 15 (1984).

43. Music, D. et al. Elastic properties of Fe-Mn random alloys studied by ab initio calculations. Applied Physics Letters 91, 191904 (2007).

44. Perdew, J. P., Burke, K. \& Ernzerhof, M. Generalized Gradient Approximation Made Simple. Physical Review Letters 77, 3865 (1996).

\section{Acknowledgements}

Funding from the German research foundation (DFG) within the priority program SPP 2006 CCA-HEA is gratefully acknowledged. DFT calculations were performed with computing resources granted by JARA-HPC from RWTH Aachen University under project JARA0131.

\section{Author Contributions}

A.M., K.G.P. and J.M.S. conceived the research. A.M. performed the experiments (except TEM), ab initio calculations and prepared the first draft of the manuscript. K.G.P. performed TEM measurements. D.M. assisted with ab initio calculations. L.W. and O.P. assisted with magnetometry measurements. J.M.S. coordinated the project. All authors were engaged in the writing of the manuscript.

\section{Additional Information \\ Competing Interests: The authors declare no competing interests.}

Publisher's note: Springer Nature remains neutral with regard to jurisdictional claims in published maps and institutional affiliations.

Open Access This article is licensed under a Creative Commons Attribution 4.0 International License, which permits use, sharing, adaptation, distribution and reproduction in any medium or format, as long as you give appropriate credit to the original author(s) and the source, provide a link to the Creative Commons license, and indicate if changes were made. The images or other third party material in this article are included in the article's Creative Commons license, unless indicated otherwise in a credit line to the material. If material is not included in the article's Creative Commons license and your intended use is not permitted by statutory regulation or exceeds the permitted use, you will need to obtain permission directly from the copyright holder. To view a copy of this license, visit http://creativecommons.org/licenses/by/4.0/.

(C) The Author(s) 2019 